\title{
An XPS Study on the Impact of Relative Humidity on the Aging of $\mathrm{UO}_{2}$ Powders
}

Scott B. Donald*, Zurong R. Dai, M. Lee Davisson, Jason R. Jeffries, and Art J. Nelson

Lawrence Livermore National Laboratory, 7000 East Ave., Livermore, CA 94550

*Corresponding author. Electronic mail: donald3@1lnl.gov

High resolution x-ray photoemission spectroscopy (XPS) was used to characterize the chemical speciation of high purity uranium dioxide $\left(\mathrm{UO}_{2}\right)$ powder samples following aging for periods of up to one year under controlled conditions with relative humidity ranging from $34 \%$ to $98 \%$. A systematic shift to higher uranium oxidation states, and thus an increase in the mean uranium valence, was found to directly correlate with the dose of water received (i.e. the product of exposure time and relative humidity). Exposure duration was found to have a greater impact on sample aging than relative humidity. The sample aged at $98 \%$ relative humidity was found to have unique structural differences for exposure time beyond 180 days when observed by scanning electron microscopy (SEM). 


\section{INTRODUCTION}

The first step in the oxidation of $\mathrm{UO}_{2}$ surfaces in wet atmospheres is the adsorption of water on the surface, initially through the physisorption of molecular $\mathrm{H}_{2} \mathrm{O}$ followed by some combination of partial $(\mathrm{H}+\mathrm{OH})$ and complete $(2 \mathrm{H}+\mathrm{O})$ dissociation to the chemisorbed products. ${ }^{1}$ Even at low temperatures, ${ }^{2,3} \mathrm{UO}_{2}$ oxidizes when exposed to air, initially forming $\mathrm{U}_{4} \mathrm{O}_{9}$ and $\mathrm{U}_{3} \mathrm{O}_{7}$ through incorporation of adventitious oxygen in the fluorite structure. Oxidation in this regime is diffusion-controlled, yielding an oxidation front with a characteristic oxygen penetration rate. The subsequent formation of $\mathrm{U}_{3} \mathrm{O}_{8}$, which at ambient conditions is the most stable compound in the U-O system, ${ }^{4}$ entails a structural transformation involving nucleation and growth kinetics. In the presence of significant quantities of water (i.e., a high relative humidity) various hydrates, hydroxides, and carbonates can form with oxidation. ${ }^{2}$

Due to the kinetics of oxygen adsorption and penetration into $\mathrm{UO}_{2}$ surfaces, oxidation is typically confined to the near-surface region. Although the structure and extent of the oxidized region has been measured using a variety of techniques, following exposure to a variety of environments, there exists no generalized model for the prediction of oxidized layer growth at ambient temperature as a function of time, relative humidity, microstructure, etc. Calorimetric measurements of the energetics of this process have been demonstrated on related actinide materials. $^{5}$ X-ray photoelectron spectroscopy (XPS) has been used previously to identify the oxidation state of uranium on the $\mathrm{UO}_{2}$ surface, indicating the extent to which it has been oxidized, ${ }^{6}$ as well as the presence and ratios of $\mathrm{O}^{2-}, \mathrm{OH}^{-}$, and $\mathrm{H}_{2} \mathrm{O}$ groups in the $\mathrm{O}$ 1s spectra to provide insight into dissociative adsorption processes at work. ${ }^{7,8,9}$ Additionally, both $\mathrm{XPS}^{5}$ and laser-induced fluorescence (LIF) spectroscopy ${ }^{10}$ measurements have been used to reveal the oxidation state of $\mathrm{U}$ on the reacted $\mathrm{UO}_{2}$ surface, indicating the extent to which the surface has 
been oxidized. Images taken from high-resolution, transmission electron microscopy (HR-TEM) have indicated the formation of an amorphous uranyl species at elevated temperatures. ${ }^{11}$

Many density functional theory (DFT) studies have attempted to clarify the molecular or dissociative character of water adsorption on various $\mathrm{UO}_{2}$ surfaces and sought to determine the atomistic processes involved in $\mathrm{H}_{2} \mathrm{O}$ adsorption during exposure of $\mathrm{UO}_{2}$ to water vapor. $^{4,12,13,14,15,16,17}$ Most DFT calculations suggest adsorption of intact $\mathrm{H}_{2} \mathrm{O}$ molecules onto pristine, low-index surfaces, but predict defective surfaces (particularly those with high concentrations of oxygen vacancies) adsorb water in a dissociative manner. Defective surfaces were also found to have more negative enthalpies of water adsorption than pristine surfaces. Because DFT results related to water and oxygen adsorption have been shown to depend on the effective Hubbard parameter, ${ }^{18}$ which corrects for $5 f$ electron correlation, care must be taken in their interpretation.

In agreement with the results from electronic structure theory, XPS measurements have indicated both molecular and dissociative adsorption. These studies additionally showed increased dissociation on defect-rich surfaces as compared to that seen on relatively pristine surfaces. ${ }^{8,19}$ Direct recoil spectroscopy (DRS) measurements indicated the same trend, showing more extensive water adsorption on defective surfaces. ${ }^{20}$ Finally, low energy ion scattering (LEIS) and electron stimulated desorption (ESD) measurements indicated the complete dissociation of $\mathrm{H}_{2} \mathrm{O}$ on surfaces exposed to water vapor in vacuum along with incorporation of the atomic oxygen into the surface with subsequent diffusion into the bulk. ${ }^{21}$

While studies have been performed measuring the structure and extent of oxidation following exposure to a range of environmental conditions, ${ }^{22}$ there currently is no generalized model for the prediction of oxidized layer growth as a function of time, relative humidity, and 
oxygen concentration. In this study, $\mathrm{UO}_{2}$ powders were aged at ambient temperature under controlled conditions and the oxidation progress was monitored as a function of relative humidity and exposure time using XPS.

\section{EXPERIMENTAL}

A large quantity of $\mathrm{UO}_{3}$ was obtained from Oak Ridge National Laboratory and used as the starting material for conversion to stoichiometric $\mathrm{UO}_{2}$. The as received powder was loaded into a tube furnace and reacted with ultra-high purity $\mathrm{H}_{2}$ at $650^{\circ} \mathrm{C}$ for 24 hours. ${ }^{23}$ The resulting powder was primarily composed of grains between 5 and $10 \mu \mathrm{m}$ in diameter with a surface area between 0.35 and $1.0 \mathrm{~m}^{2} / \mathrm{gram}$. The purity and surface stoichiometry of the reacted sample was investigated by XPS with only carbon and nitrogen in addition to the expected oxygen and uranium detected (Supp. Fig. 1). The bulk stoichiometry of the reacted powder was confirmed with powder x-ray diffraction (Supp. Fig. 2). Subsequently, samples of stoichiometric $\mathrm{UO}_{2}$ were exposed at $25{ }^{\circ} \mathrm{C}$ individually to relative humidity ranging from $34 \%$ to $98 \%$, as detailed in Table I, for a period of approximately one, three, six, nine, and twelve months to the specific humidity and $20 \% \mathrm{O}_{2}$. The relative humidity of the samples was controlled by placing inorganic salt slurries into a vacuum desiccator, which was then allowed to equilibrate to a fixed value inside the vessel and monitored with an internal hygrometer. Aliquots of these samples were then dispensed in room air and loaded in a HEPA-filtered hood onto carbon sticky tape mounted to an XPS sample holder. During the short transfer time of the samples from the controlled conditions of the desiccator to the vacuum chamber, the exposure to relative humidity of room air $(\sim 30 \% \mathrm{RH})$ is not expected to have a discernable impact on the stoichiometry of the samples. The exception to this was for the 378 day sample set, which spent 60 days in a nitrogen purged glovebox with $\sim 0 \%$ RH. 
X-ray photoelectron spectroscopy was performed on a PHI Quantum 2000 system using a focused, monochromatic Al Ka X-ray $(1486.6 \mathrm{eV})$ source for excitation and a spherical section analyzer. A $200 \mu \mathrm{m}$ diameter X-ray beam incident to the surface normal was used for analysis with the detector set at $45^{\circ}$ from the surface normal. The instrument has a 16-element multichannel detection system. Spectra were collected using a pass energy of $23.5 \mathrm{eV}$, giving an energy resolution of $0.3 \mathrm{eV}$, that when combined with the $0.85 \mathrm{eV}$ full width at half maximum (FWHM) $\mathrm{Al} \mathrm{K \alpha}$ line width gives a resolvable XPS peak width of $1.2 \mathrm{eV}^{24}$ Deconvolution of unresolved, core-level peaks was accomplished using MultiPak 9.6 (PHI) curve fitting routines with asymmetric or Gaussian-Lorentzian line shapes and a Shirley background. Low energy electrons and argon ions were used for specimen charge neutralization. The collected data were referenced to an energy scale with binding energies for $\mathrm{Cu} 2 \mathrm{p}_{3 / 2}$ at $932.7 \pm 0.1 \mathrm{eV}$ and $\mathrm{Au} 4 \mathrm{f}_{7 / 2}$ at $84.0 \pm 0.1 \mathrm{eV}$. Binding energies were also referenced to the $\mathrm{C} 1 \mathrm{~s}$ photoelectron line arising from adventitious carbon at $284.8 \mathrm{eV}$.

Scanning electron microscopy (SEM) was demonstrated on the JEOL JSM-7401 FESEM, an ultra-high resolution instrument with cold field emission electron gun, operating at an accelerating voltage of $5 \mathrm{kV}$. Similar to that for XPS, aliquots of powder samples were dispensed in room air and loaded in a HEPA-filtered hood onto carbon sticky substrates attached to SEM stubs and then looked at under SEM immediately to minimize the extra exposure time in the room air. Both secondary electron and backscattered imaging techniques were collected to characterize the differentiation in morphology and surface texture of individual grains and agglomerates for each sample subjected to different exposure conditions and time

\section{RESULTS}


Figure 1 presents the XPS $\mathrm{U} 4 f_{7 / 2,5 / 2}$ core-level spectra for the aged $\mathrm{UO}_{2}$ powders as a function of exposure time at $56 \%$ relative humidity and $20 \%$ oxygen. Following increasing exposure times, the peaks were found to shift to higher binding energies, corresponding to an increase of the overall valence of the uranium. Curve fitting of the $U 4 f_{7 / 2,5 / 2}$ spin-orbit pair for the aged samples revealed three $4 f_{7 / 2}$ components at $380.0 \mathrm{eV}, 380.8 \mathrm{eV}$, and $381.7 \mathrm{eV}$ indicative of $\mathrm{U}^{4+}, \mathrm{U}^{5+}$, and $\mathrm{U}^{6+}$ respectively. ${ }^{6,9}$ Component analyses for the $\mathrm{U} 4 f_{7 / 2}$ spectra are graphically displayed in Figure 1 to show the uranium speciation of the starting material and the variation from 30 to 378 days with exposure to $56 \% \mathrm{RH}$ and $20 \% \mathrm{O}_{2}$.

Variation in uranium $4 \mathrm{f}_{7 / 2}$ speciation as a function of time for each relative humidity is displayed in Figure 2. The starting material was found to be predominantly $\mathrm{U}^{4+}$, in line with expectations of a $\mathrm{UO}_{2}$ starting material, and a small portion as $\mathrm{U}^{5+}$, likely a result of slight oxidation on the surface from exposure to atmospheric oxygen and water. For all samples, the relative amount of uranium in the $4+$ and $5+$ valences decreased and $6+$ increased with time. The samples at $56 \%$ and $98 \% \mathrm{RH}$ showed a slight increase in the relative amount as $\mathrm{U}^{5+}$ from 30 to 90 days of exposure, perhaps indicating the $4+$ to $5+$ conversion proceeds proportionate to relative humidity, while the $5+$ to $6+$ conversion may not, creating an elevated relative concentration of $\mathrm{U}^{5+}$ from the increased reaction rate at higher relative humidity.

Based on previous studies of room temperature oxidation of uranium oxides mentioned previously, the oxidation process should tail off and effectively stop due to saturation effects somewhere between $\mathrm{U}_{3} \mathrm{O}_{8}$ and $\mathrm{UO}_{3}$. At this point, it would be expected the mean uranium valence would maintain this equilibrium value while under constant atmospheric conditions. This endpoint appears to have been observed in the 378 day sample aged at $98 \% \mathrm{RH}$, which showed no increase in mean uranium valence from 270 days. In contrast, the 378 day samples 
aged at $34 \%$ and $56 \%$ RH displayed a decrease in the mean uranium valence as compared to the 270 day samples. We attribute this to the history of the 378 day sample set, as this powder set spent an anomalous and significantly greater amount of time out of the exposure chamber and in a $\mathrm{N}_{2}$ purged glovebox with $0 \% \mathrm{RH}$ prior to XPS analysis (all previous samples were loaded on carbon sticky tape and analysis began within 24 hours). This variation likely explains the observed results, and we are currently investigating changes in oxidation state of aged powders when stored under non-oxidizing conditions at atmospheric pressure.

The $\mathrm{O} 1 \mathrm{~s}$ core-level spectra for the $\mathrm{UO}_{2}$ samples aged at $56 \% \mathrm{RH}$ as a function of exposure duration are presented in Figure 3. The $\mathrm{O}$ 1s structure is dominated by an oxide peak at $530.2 \mathrm{eV}$ for the sample aged 30 days, which shifts to higher binding energies for samples exposed to greater duration, ultimately positioned at $531.4 \mathrm{eV}$ for the sample aged for 378 days. This shift is consistent with that seen for increasingly oxidized uranium species and is in agreement with the variation in the mean uranium valence described previously. The samples aged at $56 \%$ relative humidity for more than 90 days also presented a lower binding energy shoulder at $529.8 \mathrm{eV}$, which upon peak fitting is revealed as a U-O-U peak relating to " $\mathrm{O}^{2-}$ in the equatorial plane of the uranium polyhedral". ${ }^{7}$

The intensity of the slight U-O-U shoulder seen at 90 days for both the $56 \%$ and $98 \% \mathrm{RH}$ samples was found to grow in intensity with increased exposure to relative humidity, as detailed in Figure 4. However, the relative amount of oxygen as U-O-U appears to vary independently with time. Interestingly, the $\mathrm{H}_{2} \mathrm{O}$ and $\mathrm{OH}^{-}$peak areas have an approximate ratio of 1:3 for the 98\% RH samples for all times in the exposure series. In contrast, the ratio varies between 1:1.5 and 1:8 for the other relative humidities. Future efforts will work to elucidate if the ratios of $\mathrm{O}^{2-}$, 
$\mathrm{OH}^{-}$, and $\mathrm{H}_{2} \mathrm{O}$ provide insight into the current oxidation state of the uranium as well as the dissociative mechanisms at work.

The C $1 s$ core-level spectra for the uranium oxide powders aged at $56 \% \mathrm{RH}$ for between 30 and 378 days are presented in Figure 5. The binding energies of the deconvolved C $1 s$ peak are determined to be at $284.8 \mathrm{eV}, 286.0 \mathrm{eV}, 287.8 \mathrm{eV}$, and $289.5 \mathrm{eV}$ representing $\mathrm{C}-\mathrm{H}, \mathrm{C}-\mathrm{O}$, $\mathrm{C}=\mathrm{O}$, and $\mathrm{O}-\mathrm{C}=\mathrm{O}$ bonding, respectively ${ }^{25}$ Based on the speciation of the starting material, there is a significant amount of carbon found in the near-surface area prior to aging, likely a mix of carbon found in the $\mathrm{UO}_{3}$ starting material and from adsorption of adventitious carbon. Between 90 and 180 days, the peak binding energy was found to shift from $284.8 \mathrm{eV}$ to $286.0 \mathrm{eV}$, indicative of a change in the primary speciation of the sample from $\mathrm{C}-\mathrm{H}$ to $\mathrm{C}-\mathrm{O}$. Component analyses of the C 1s spectra are graphically summarized in Figure $\mathbf{6}$ to show the variation of carbon speciation with time for each studied relative humidity. In all cases, the relative amount of $\mathrm{C}-\mathrm{O}$ was found to increase with time while that of $\mathrm{C}-\mathrm{H}$ decreased. For the samples aged at $56 \% \mathrm{RH}$ and $98 \% \mathrm{RH}$, the $\mathrm{C}-\mathrm{H}$ and $\mathrm{C}-\mathrm{O}$ relative contributions appear to stabilize with time at $27 \%$ and $57 \%$ respectively, with the remaining carbon being split between $\mathrm{C}=\mathrm{O}$ and $\mathrm{O}-\mathrm{C}=\mathrm{O}(5 \%$ to $10 \%$ relative contributions). For all samples taken for a duration greater than 90 days, the ratio of the $\mathrm{C}-\mathrm{O}$ and $\mathrm{O}-\mathrm{C}=\mathrm{O}$ peaks is approximately 10:1, with the $56 \% \mathrm{RH}$ exposure series displaying a smaller ratio (i.e. 8:1) at 270 and 378 days.

Figure 7 displays backscattered electron SEM images collected from some of samples involved in present study, showing typical morphologies of constitutive materials occurring in corresponding samples. The $\mathrm{UO}_{3}$ powder used as a starting material consists of predominant micron-size tabular grains and some sub-micron granular particles, which agglomerate together and both have smooth and faceted surfaces (Fig. 7a). During reduction from $\mathrm{UO}_{3}$ to $\mathrm{UO}_{2}$, the 
tabular $\mathrm{UO}_{3}$ grains collapsed due to a large volume contraction, leading to the resultant stoichiometric $\mathrm{UO}_{2}$ particles possessing a bumpy surface with heavy cracking (Fig. 7b). Following aging of the stoichiometric $\mathrm{UO}_{2}$ powders at $34 \%$ relative humidity and $20 \% \mathrm{O}_{2}$ for 180 days, the particles became more granular and their surfaces smoothed while the density of cracks dramatically decreased (Fig. 7c), a tendency which continued as the aging time increased. For the sample exposed to $34 \%$ relative humidity for 330 days (Fig. 7e), faceted grains were observed. Large tabular shaped grains were found occurring in the samples exposed to $98 \%$ relative humidity for 180 days (Fig. 7d) and 330 days (Fig. 7f), which were intergrown with small granular particles displaying characteristic cracks on them. Additional characterization of the aged powders using transmission electron microscopy (TEM) and electron energy loss spectroscopy (EELS) is currently underway. Preliminary analyses indicate that the large tabular grains are likely an amorphous uranyl-related phase, possibly dehydrated schoepite, and the small granular particles maintained the fcc fluorite structure found in bulk $\mathrm{UO}_{2}$.

The unique structure seen only for aging at $98 \%$ RH perhaps served to buffer the sample against the reduction observed in the other 378 day samples during storage at $0 \% \mathrm{RH}$. Based on comparison between the SEM images and XPS O 1s speciation for samples aged at $98 \% \mathrm{RH}$, the growth of the U-O-U peak in XPS at $528 \mathrm{eV}$ appears to correlate to the growth of the large, tabular grains observed by SEM. However, the appearance of the U-O-U peak in XPS with exposure time at lower RH did not correspond to similar morphological changes in the powders, an indication the U-O-U peak appearance may be unrelated. This structural change observed in SEM may be unique to aging at an elevated relative humidity and could serve to provide a distinguishable indicator of exposure to relative humidity above a certain percentage for aged $\mathrm{UO}_{2}$ powders and further work is planned to understand the growth and nature of the grains. 


\section{DISCUSSION}

\subsection{Comparison between Impact of Exposure Duration to Relative Humidity}

To rule out the effect of systematic contamination during aging, the variation in the relative elemental composition as a function of time or relative humidity only was calculated by averaging across the three relative humidity or five exposure times respectively. When averaged across all humidities, the relative amount of uranium and oxygen on the surface and near surface bulk was found to decrease with time, while carbon and nitrogen both increased with time (Figure 8a). This likely indicates some form of systematic impurity in the exposure setup that accumulates with time. A deviation from this trend was observed for the 378 day samples and is attributed to their unique handling characteristics prior to XPS analysis. However, there was no correlation found between relative abundance of the elements found in the samples (i.e. $\mathrm{U}, \mathrm{O}, \mathrm{C}$, and $\mathrm{N}$ ) averaged across all times with relative humidity (Figure 8b), which we believe shows any contamination taking place during exposure is independent of the sample's relative humidity. Note the relative abundance of nitrogen is complicated from overlap between the XPS N 1s and satellite structure of the $\mathrm{U}_{4 \mathrm{f}_{5 / 2}}$ peak, particularly from $\mathrm{U}^{5+} \cdot{ }^{26}$ As nitrogen is seen in the starting material, due to less overlap with the $\mathrm{U}^{4+}$ satellite, it appears to be a minor contaminant present through the entirety of the process, likely from the $\mathrm{UO}_{3}$ precursor.

As shown previously, the relative abundance of uranium at higher valences was found to increase with both time and increased relative humidity. In place of uranium speciation, it can be useful to instead plot the variation in mean uranium valence as a function of relative humidity and exposure duration to better understand the relative impact of each factor. Based on the speciation results and calculated mean uranium valence from XPS analysis, exposure time (Figure 9a) was found to have a greater impact than exposure humidity (Figure 9b) on changes to 
uranium speciation / increase in the mean uranium valence (e.g. exposure to $34 \% \mathrm{RH}$ for 270 days resulted in a more oxidized powder than the 56\% sample aged for 180 days which in turn was more oxidized than the $98 \%$ RH aged for 90 days, relevant points have been enlarged and given a black border in Figure $9 b$ ). Additionally, while the value of the $\mathrm{O} / \mathrm{U}$ ratio doesn't seem to correlate to aging at higher relative humidity, it does directly relate to an increase in the mean uranium valence; supporting the previous point that exposure time has a greater impact on sample oxidation than relative humidity.

Furthermore, while the mean uranium valence is ultimately limited to fully +6 , the rate of change in mean uranium valence as a function of relative humidity (roughly estimated as the slope of the lines shown in Figure 9b) appears to decrease with time prior to reaching this limit. This is perhaps an indication of a change in the predominant mechanism for the samples as they oxidized from $\mathrm{UO}_{2}$ to $\mathrm{U}_{4} \mathrm{O}_{9}, \mathrm{U}_{3} \mathrm{O}_{8}$, and additional intermediate species. By plotting the mean uranium valence of commonly occurring uranium oxides onto Figure 9a, it can be determined that the oxidation from $\mathrm{UO}_{2}$ to $\mathrm{U}_{4} \mathrm{O}_{9} / \mathrm{U}_{3} \mathrm{O}_{7}$ appears to occur facilely, with only the 30 day sample aged at $34 \% \mathrm{RH}$ being less oxidized than $\mathrm{U}_{3} \mathrm{O}_{7}$. Given this step only involves incorporation of oxygen into vacancies present in the existing fluorite structure, the relatively quick nature of this step is expected. Subsequent oxidation to $\mathrm{U}_{3} \mathrm{O}_{8}$ proceeded more slowly, taking between 60 to 150 additional days for $98 \%$ and $34 \%$ RH respectively, with the decreased rate likely a result of the change from a cubic to orthorhombic crystal structure. Ultimate oxidation to $\mathrm{UO}_{3}$ appears to proceed even less quickly, and appears to occur independently of relative humidity. Further work is planned for shorter exposure durations (time $<30$ days) to clarify the oxidation process from $\mathrm{UO}_{2}$ to $\mathrm{U}_{4} \mathrm{O}_{9}$. 
Comparisons between the speciation of the composition elements were also made (shown visually as Figure 10), and the following general trends were observed:

1) Samples with higher relative amounts of $\mathrm{O} 1 \mathrm{~s}$ as $\mathrm{H}_{2} \mathrm{O}$ and $\mathrm{OH}^{-}$tend to be less oxidized (possess a lower mean uranium valence) while sample with greater relative amounts of $\mathrm{O}=$ and $\mathrm{U}-\mathrm{O}-\mathrm{U}$ tend to be more oxidized (i.e. a greater percentage of the $\mathrm{U} 4 \mathrm{f}_{7 / 2}$ was found as $\left.\mathrm{U}^{6+}\right)$.

2) Overall, the $\mathrm{C}$ 1s speciation was found to correlate less well to uranium speciation than the $\mathrm{O} 1 \mathrm{~s}$. However, samples with higher relative amounts of $\mathrm{CH}$ tend to be less oxidized while samples with a higher relative amount of $\mathrm{CO}$ tend to be more oxidized, and the $\mathrm{CH}$ to $\mathrm{CO}$ ratio does serve to provide some insight into the overall oxidation state of the uranium present in the samples.

\subsection{Predictive Formalism for $\mathrm{UO}_{2}$ Powder Oxidation}

The speciation of all samples was plotted against mean uranium valence and shown in Figure 11. Speciation of samples at a given mean uranium valence appears to be independent of exposure duration or relative humidity, possibly indicating the oxidation pathway is not dependent on water partial pressure over the course of one year, only the rate at which the reaction proceeds.

Based on this, the product of relative humidity and exposure duration is defined simply as "dose" and plotted as the logarithm against the XPS calculated mean uranium valence in Figure 12. The line shown is a linear best fit for the data. This simple mathematical formalism appears to effectively capture the relationship between effective dose and resulting mean uranium valence, allowing predictions to be made for time and relative humidity exposure not 
experimentally measured. However, the accuracy of the model is questionable under low dose conditions, due to the lack of data available for a mean uranium valence less than that of $\mathrm{U}_{4} \mathrm{O}_{9}$ (i.e. +4.25), and high dose conditions; for example, at an effective dose that is roughly equivalent to 2 years at $98 \% \mathrm{RH}$ the mean uranium valence would become greater than +6 , a non-physical conclusion. Given the apparent swift nature of the oxidation to $\mathrm{U}_{4} \mathrm{O}_{9} / \mathrm{U}_{3} \mathrm{O}_{7}$, additional work on oxidation of $\mathrm{UO}_{2}$ powders at low effective doses of $\mathrm{H}_{2} \mathrm{O}$ is currently planned to gain further insight into the process.

If instead a relationship between effective dose and mean uranium valence is created for each relative humidity, as shown is Figure 13, we can see that for the same effective dose of $\mathrm{H}_{2} \mathrm{O}$, the lowest relative humidity appears to have the greatest increase in the mean uranium valence, implying the reaction proceeds more efficiently when the powders are exposed to less water. This could possibly indicate the oxidation of $\mathrm{UO}_{2}$ powders is driven not only by the flux of water molecules striking the surface, but also is somewhat rate limited by diffusion of dissociation products (i.e. $\mathrm{O}^{2-}$ and $\mathrm{OH}^{-}$) from the surface into the bulk, a process which would be dependent on the local temperature instead of on the flux of molecules striking the surface of the powder.

\section{SUMMARY and CONCLUSIONS}

Exposure of stoichiometric $\mathrm{UO}_{2}$ to different relative humidity and $\mathrm{O}_{2}$ levels has been accomplished using glass vacuum desiccators. Humidity was controlled by use of different saturated inorganic salts, with options ranging from $11 \%$ to $98 \%$, and was monitored with a hygrometer. A series of stoichiometric $\mathrm{UO}_{2}$ sample exposures were initiated simultaneously and surface oxidation was compared using X-ray photoelectron spectroscopy at exposure times of up 
to twelve months. The following general trends were observed for the elemental speciation of the samples when comparing the impact of exposure conditions to exposure time:

1) In the $U$ 4 f spectra, $U^{4+}$ was found to decrease with both time and relative humidity, while $\mathrm{U}^{6+}$ increased with both, indicating oxidation of the powders. In line with the peak fits, the mean valence of uranium was found to increase with time for all relative humidities, progressing most quickly for the sample exposed to $98 \%$ relative humidity.

2) In the $\mathrm{O}$ 1s spectra, $\mathrm{H}_{2} \mathrm{O}$ and $\mathrm{U}-\mathrm{O}-\mathrm{U}$ increase with relative humidity while $\mathrm{OH}-$ and $\mathrm{O}=$ decrease. Water and $\mathrm{OH}-$ relative amounts were found to decrease with time, and $\mathrm{O}=$ and $\mathrm{U}-\mathrm{O}-\mathrm{U}$ both increase with time. A systematic increase in O1s binding energy was observed with increasing relative humidity, in agreement with the increased oxidation of the samples

3) In the $C$ 1s spectra, for both duration of exposure and relative humidity, the relative amount of $\mathrm{C}-\mathrm{O}$ and $\mathrm{COO}$ increased, $\mathrm{CH}$ decreased, and $\mathrm{C}=\mathrm{O}$ varied independently.

All samples were found to oxidize to a mean uranium valence between $\mathrm{U}_{3} \mathrm{O}_{8}$ and $\mathrm{UO}_{3}$ by 378 days, and the rate of oxidation was found to decrease over time, likely changing due to variation in the oxidation mechanism and required structural reconfigurations during incorporation of the additional oxygen atoms. However, SEM images of the sample exposed to 98\% RH displayed unique morphological features consistent with amorphous uranyl species following aging for 180 days. Finally, exposure time was found to have a greater impact on extent of powder oxidation as compared to relative humidity.

\section{ACKNOWLEDGEMENTS}


This work was performed under the auspices of the U.S. Department of Energy by Lawrence Livermore National Laboratory under Contract DE-AC52-07NA27344 and was funded by the Office of Defense Nuclear Nonproliferation Research and Development within the U.S. Department of Energy's National Nuclear Security Administration under Project Number LL15-U_Surface_Oxidation-NDD3B. 
Table 1. Initial Exposure Conditions for Stoichiometric $\mathrm{UO}_{2}$

\begin{tabular}{l|l} 
Salt Slurry & Relative Humidity \\
\hline $98 \% \mathrm{CaCl}_{2} \cdot 6 \mathrm{H}_{2} \mathrm{O}$ & $34 \%$ \\
$\left.99 \% \mathrm{Mg}_{\mathrm{NO}}\right)_{2} \cdot 6 \mathrm{H}_{2} \mathrm{O}$ & $56 \%$ \\
$99 \% \mathrm{~K}_{2} \mathrm{SO}_{4}$ & $98 \%$
\end{tabular}




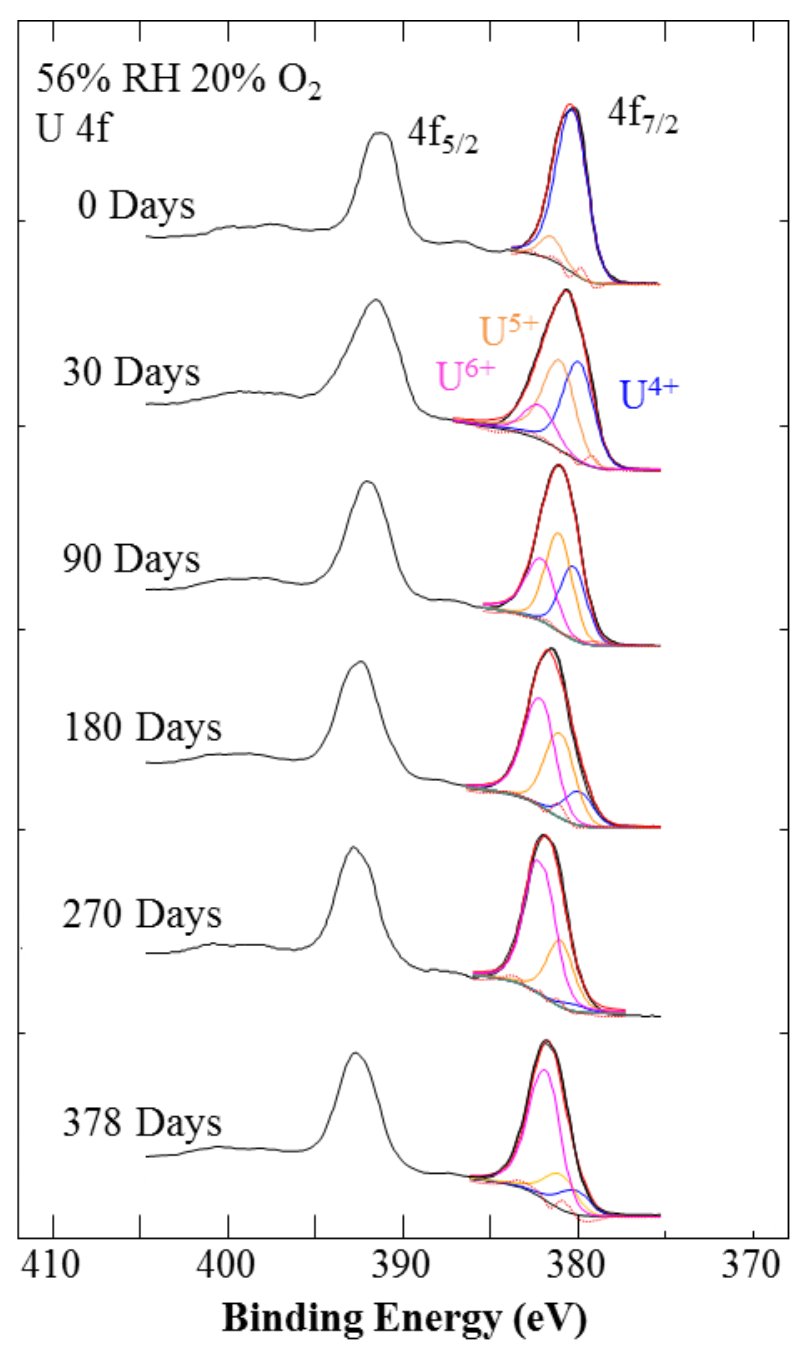

Figure 1: XPS U 4f $\mathrm{f}_{7 / 2,5 / 2}$ core-level spectra and curve fits for aging of $\mathrm{UO}_{2}$ powders at $56 \% \mathrm{RH}$ and $20 \% \mathrm{O}_{2}$ 


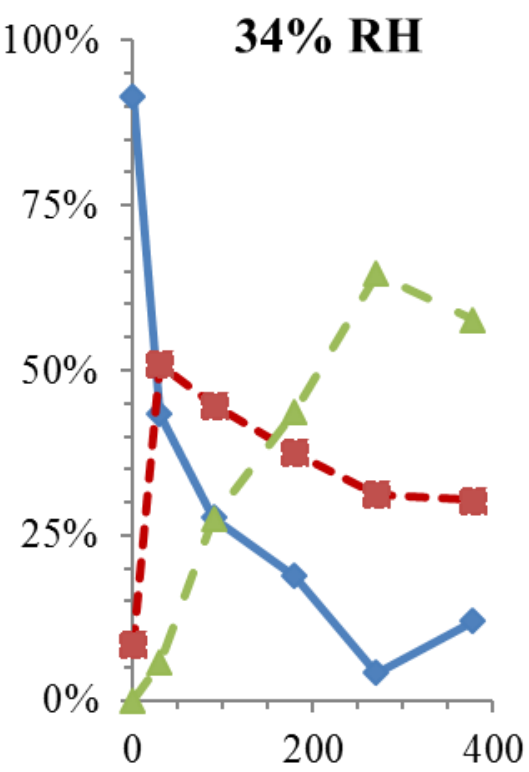

a) Exposure Time (days)

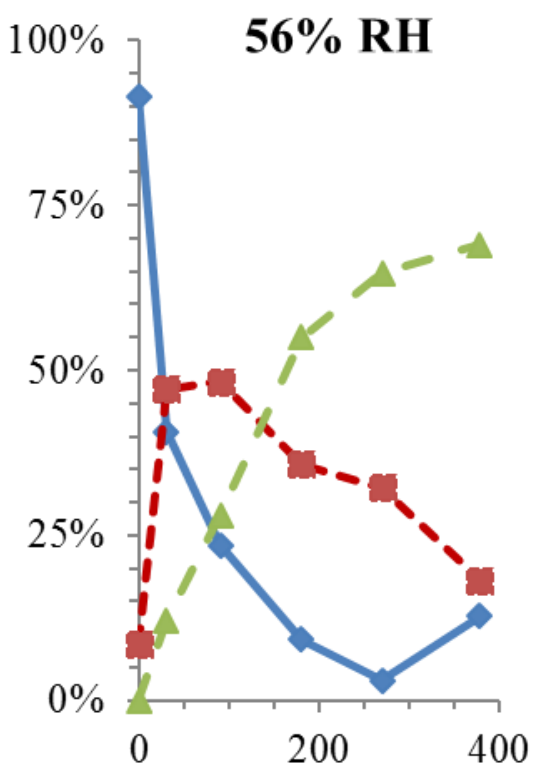

b) Exposure Time (days)

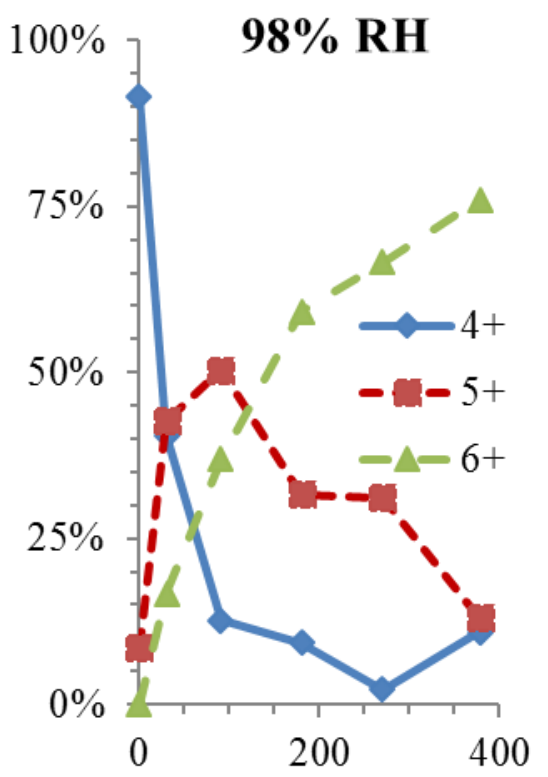

c) Exposure Time (days)

Figure 2: Variation in uranium speciation with time for the specified relative humidities from XPS analysis of the U 4 f peak 


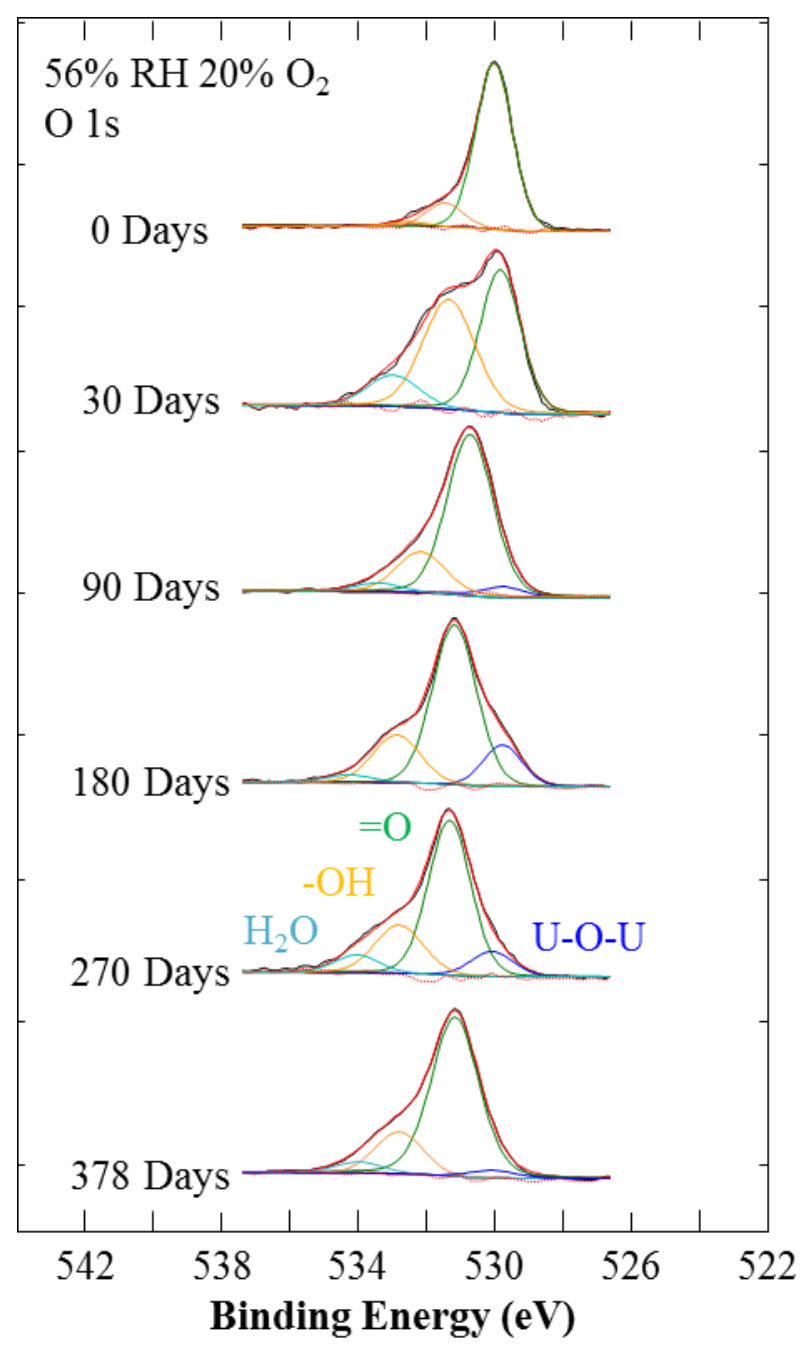

Figure 3: XPS O 1s core-level spectra and curve fits for aging of $\mathrm{UO}_{2}$ powders at $56 \% \mathrm{RH}$ and $20 \% \mathrm{O}_{2}$ 


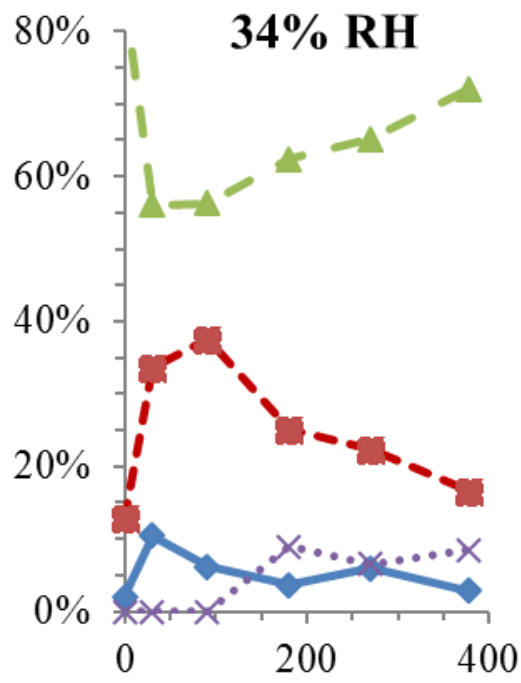

a) Exposure Time (days)

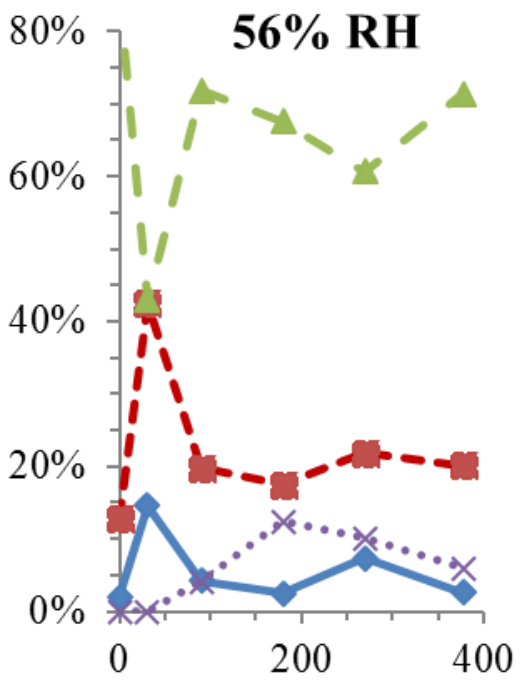

b) Exposure Time (days)

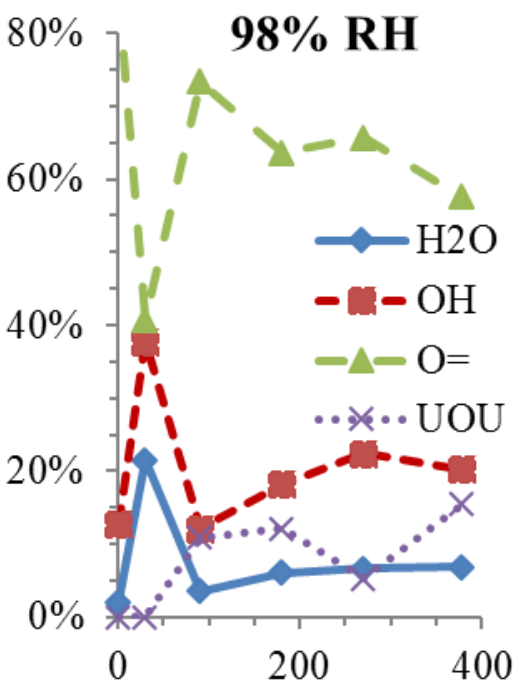

c) Exposure Time (days)

Figure 4: Variation in oxygen speciation with time for the specified relative humidities from XPS analysis of the $\mathrm{O} 1 \mathrm{~s}$ peak 


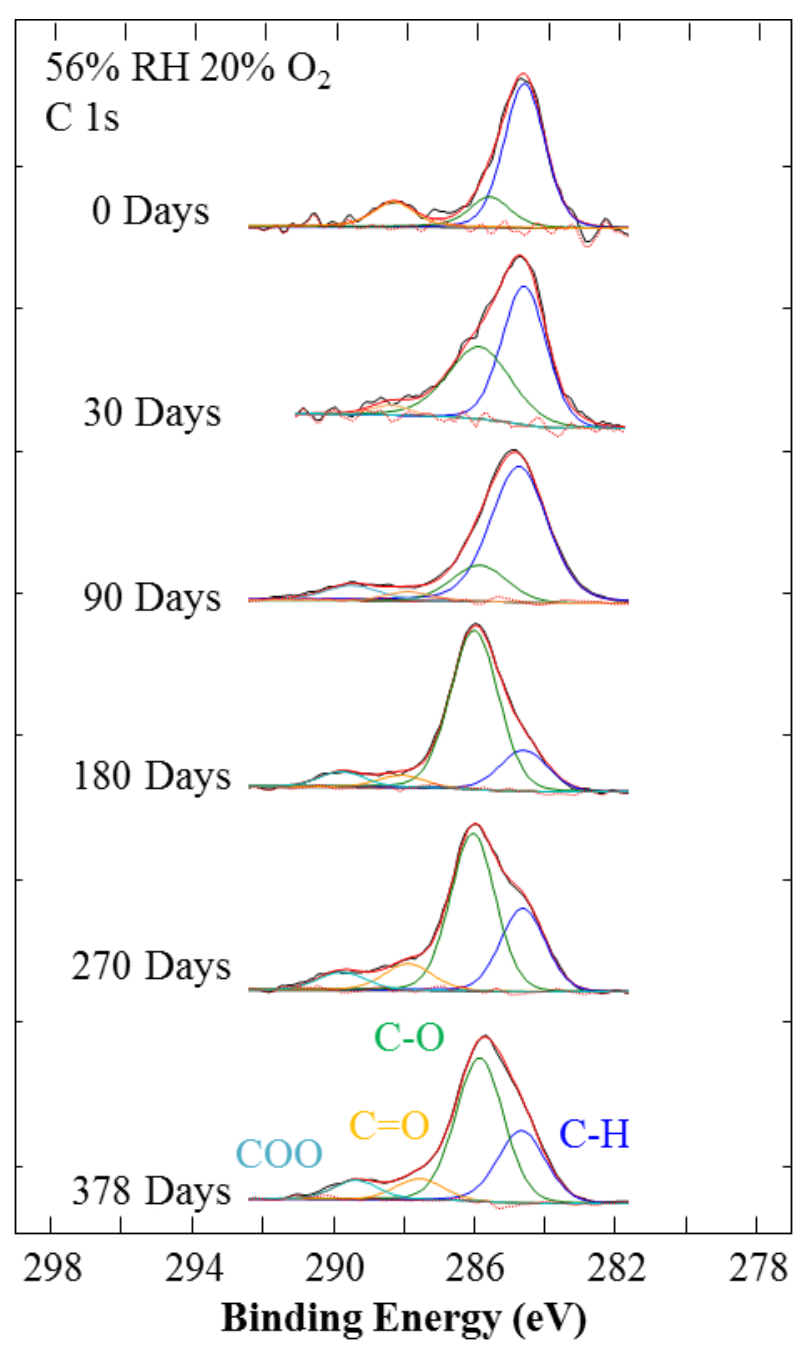

Figure 5: XPS C 1s core-level spectra and curve fits for aging of $\mathrm{UO}_{2}$ powders at $56 \% \mathrm{RH}$ and $20 \% \mathrm{O}_{2}$ 


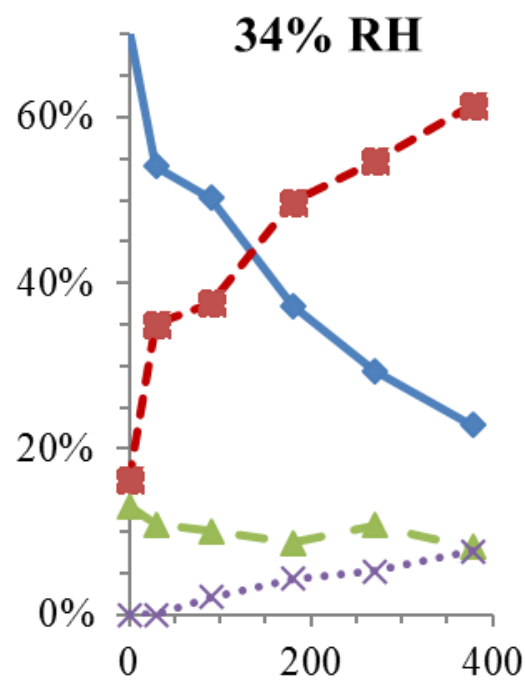

a) Exposure Time (days)

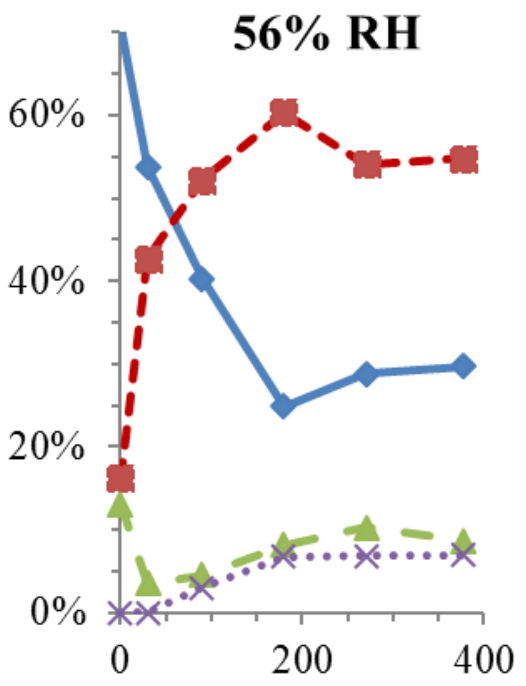

b) Exposure Time (days)

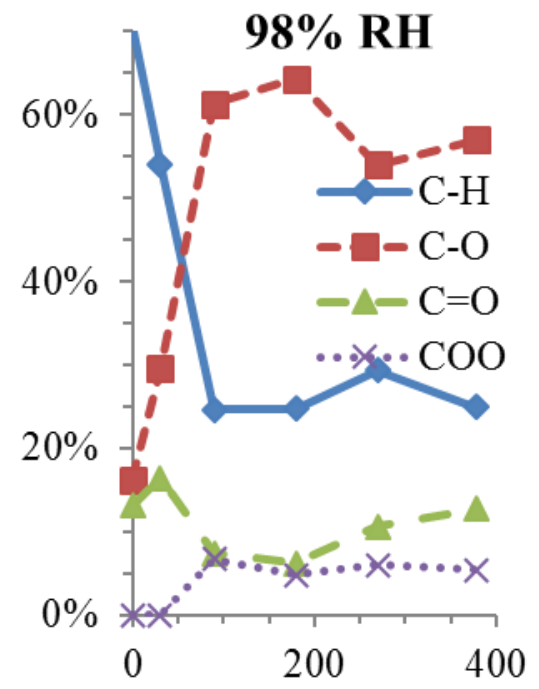

c) Exposure Time (days)

Figure 6: Variation in carbon speciation with time for the specified relative humidities from XPS analysis of the $\mathrm{C} 1 \mathrm{~s}$ peak 

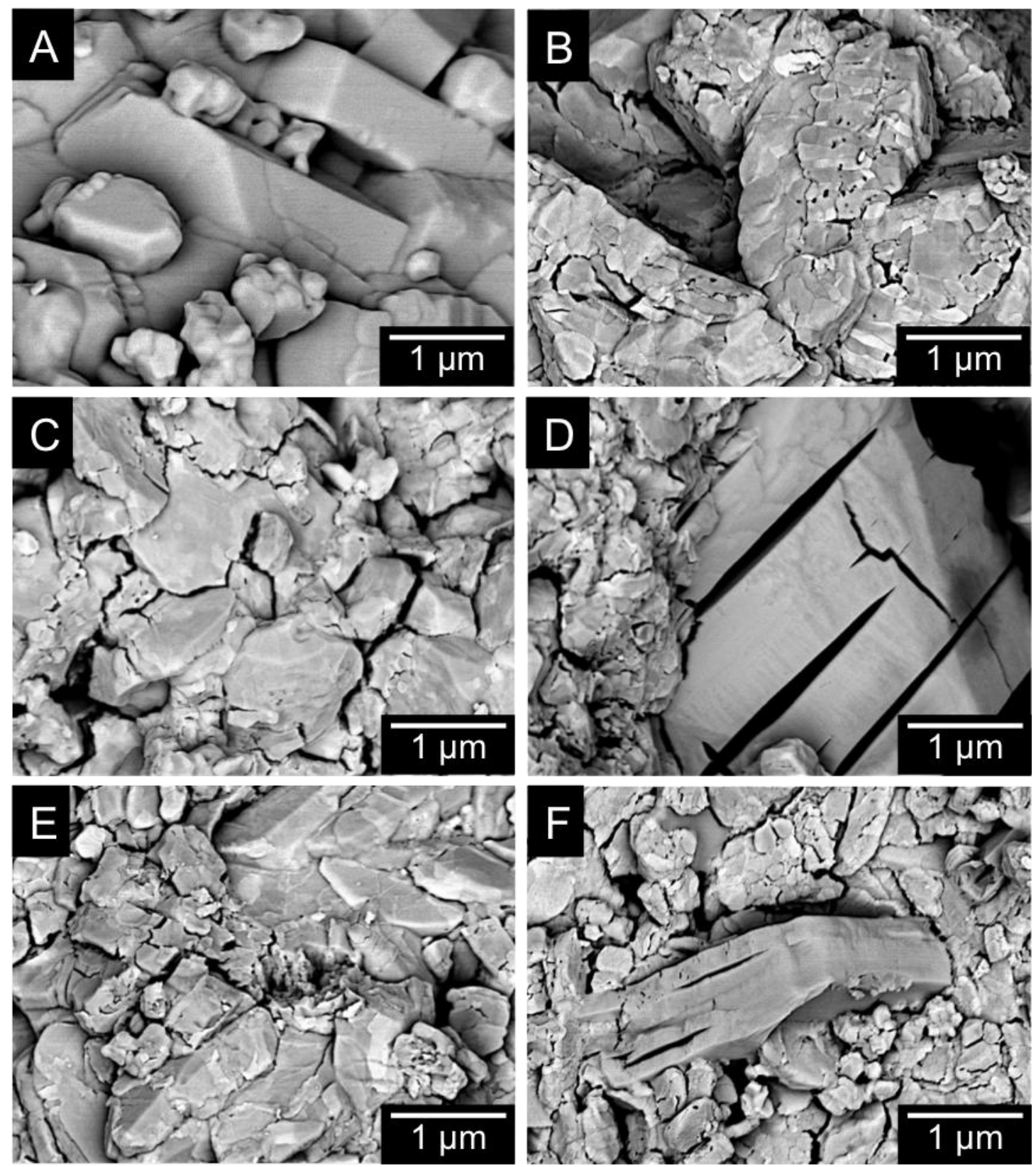

Figure 7: Backscattered electron SEM images of (a) $\mathrm{UO}_{3}$ powder used as starting material, (b) stoichiometric $\mathrm{UO}_{2}$ powders transformed from the $\mathrm{UO}_{3}$ starting material by reduction in $\mathrm{H}_{2}$ at $650^{\circ} \mathrm{C}$ for 24 hours, and samples of the stoichiometric $\mathrm{UO}_{2}$ exposed to $20 \% \mathrm{O}_{2}$ with (c) $34 \%$ relative humidity for 180 days, (d) $98 \%$ relative humidity for 180 days, (e) $34 \%$ relative humidity for 330 days, (f) and $98 \%$ relative humidity for 330 days, respectively. 

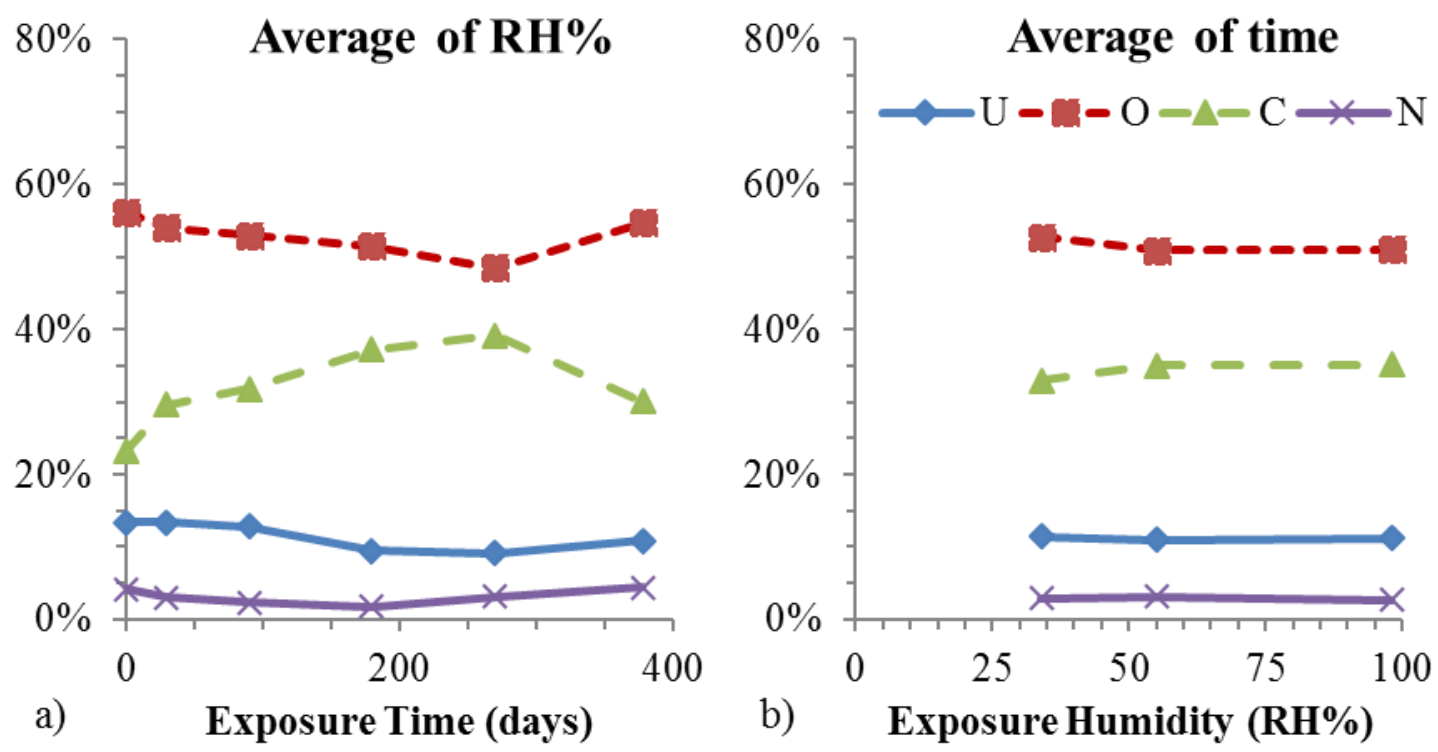

Figure 8: Variation in elemental composition from analysis of XPS core level spectra as a function of (a) exposure duration and (b) relative humidity for the $\mathrm{UO}_{2}$ powders. 

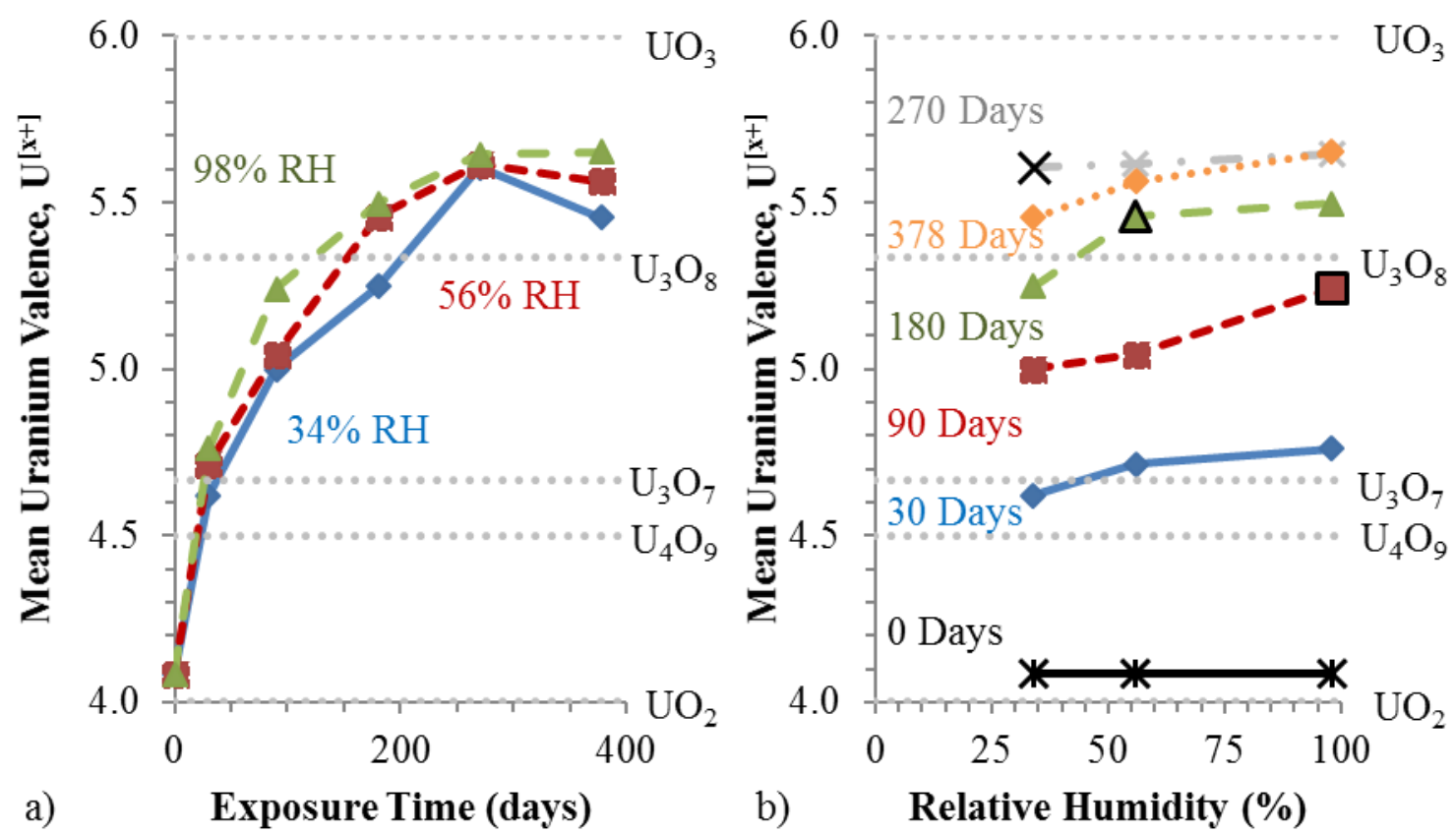

Figure 9: Comparison of the change in mean uranium valence as a function of exposure time and relative humidity. Note the relatively minimum separation as a function of relative humidity as compared to exposure duration. 

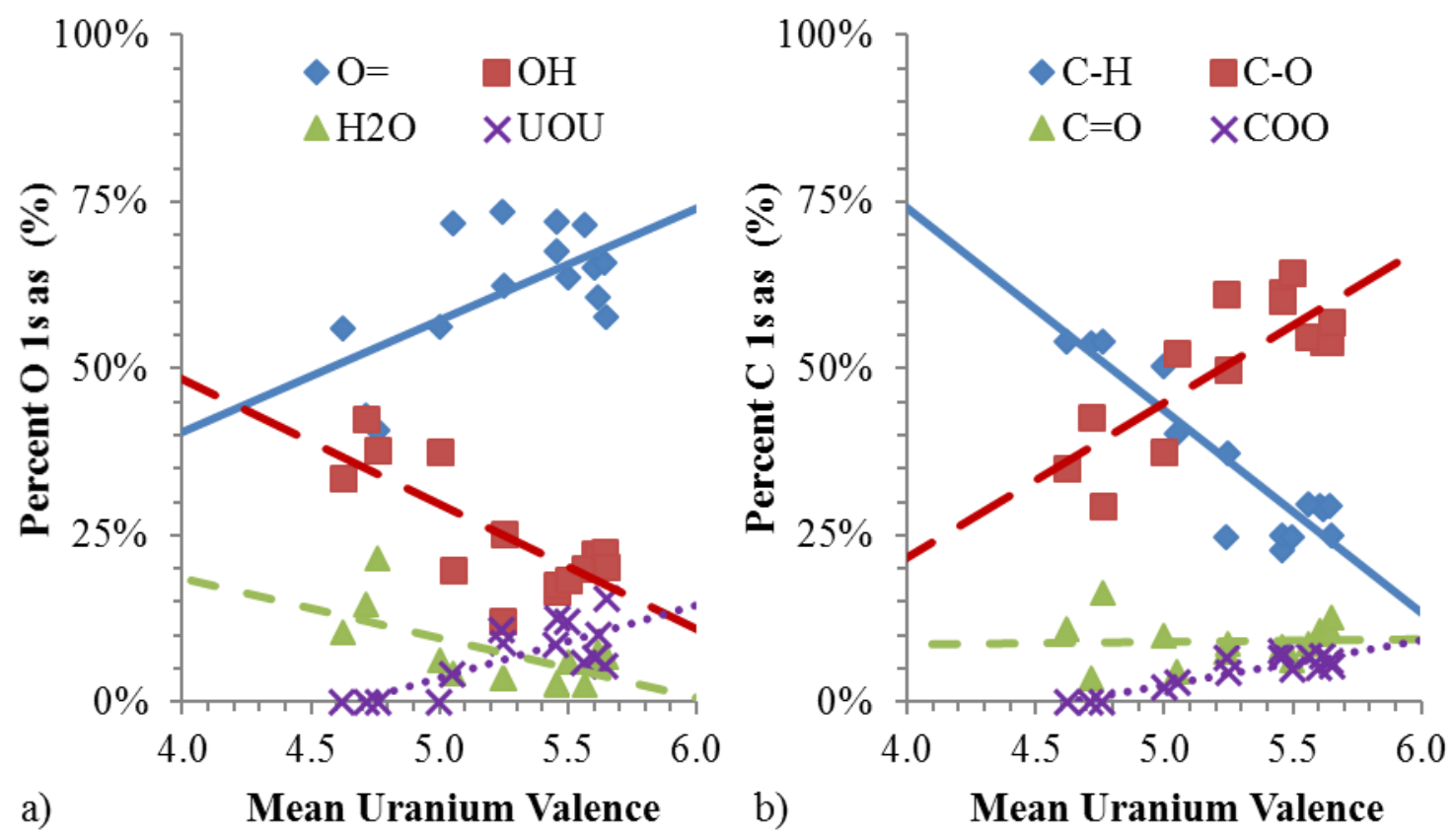

Figure 10: Comparison of the mean uranium valence to the relative speciation of the XPS O 1s and $\mathrm{C}$ 1s peaks. 


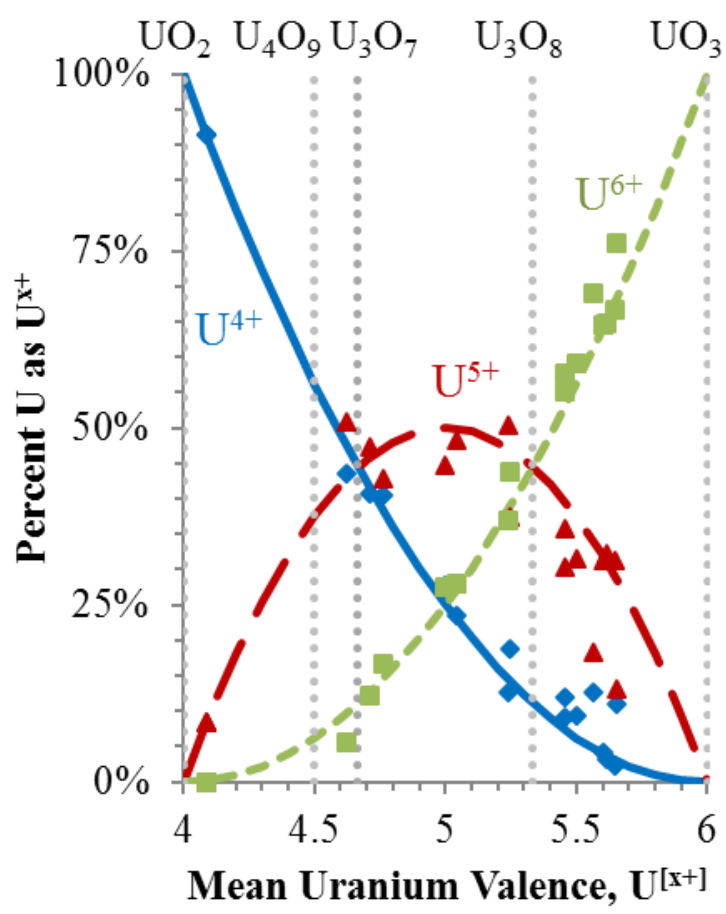

Figure 11: Comparison of the mean uranium valence to the relative percent of uranium in specific valences as determined from analysis of the XPS U $4 \mathrm{f}$ peaks. 


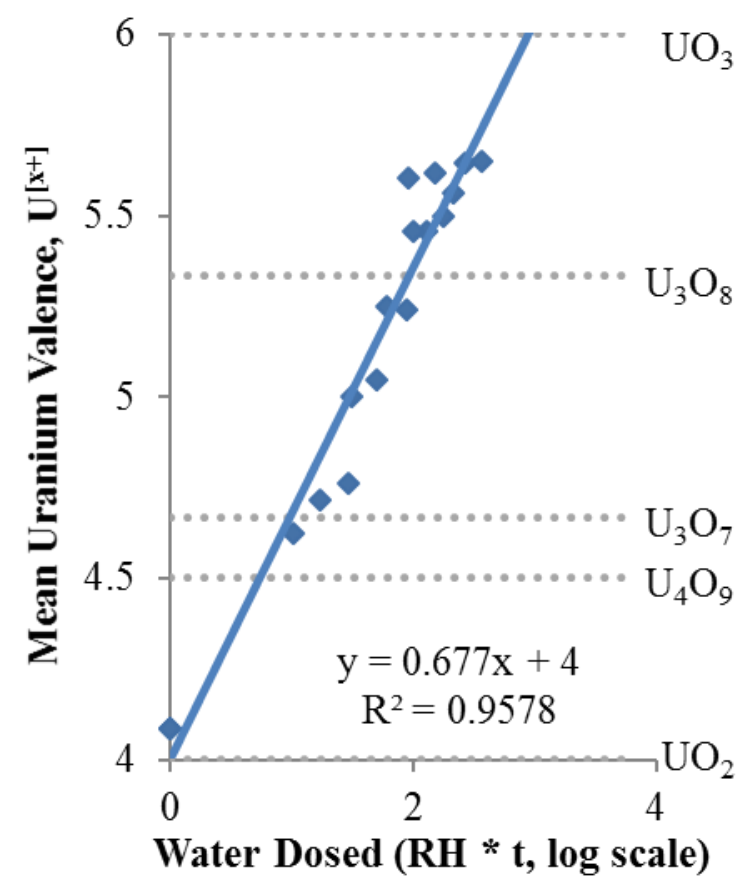

Figure 12: Comparison of mean uranium valence to effective water dose (plotted on a log scale). 


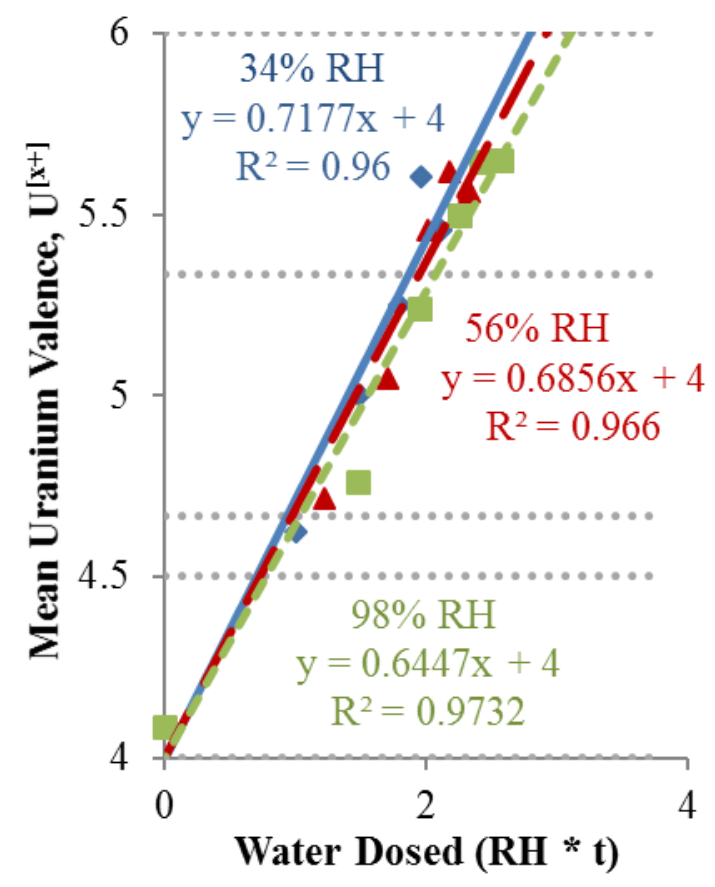

Figure 13: Comparison of mean uranium valence to effective water dose (plotted on a log scale) for the three exposure conditions of this study $(34 \%, 56 \%$, and $98 \% \mathrm{RH})$. 


\section{REFERENCES}

${ }^{1}$ E. Tiferet, M. H. Mintz, I. Jacob, N. Shamir, "Inhibition of Hydrogen Chemisorption on Uranium Surfaces by Traces of Water Vapor" Surf. Sci. 601 (2007) 4925

${ }^{2}$ G. Rousseau, L. Desgranges, F. Charlot, N. Millot, J.C. Nièpce, M. Pijolat, F. Valdivieso, G. Baldinozzi, J.F. Bérar, "A detailed study of $\mathrm{UO}_{2}$ to $\mathrm{U}_{3} \mathrm{O}_{8}$ oxidation phases and the associated rate-limiting steps" J. Nucl. Mater. 355 (2006) 10.

${ }^{3}$ R.J. McEachern, P. Taylor, "A review of the oxidation of uranium dioxide at temperatures below $400^{\circ}$ C" J. Nucl. Mater. 254 (1998) 87.

${ }^{4}$ L. Desgranges, G. Baldinozzi, G. Rousseau, J.C. Nièpce, G. Calvarin, "Neutron Diffraction Study of the in Situ Oxidation of $\mathrm{UO}_{2}$ " Inorg. Chem. 48 (2009) 7585.

${ }^{5}$ V. Alexandrov, T.Y. Shvareva, S. Hayun, M. Asta, A. Navrotsky, "Actinide Dioxides in Water: Interactions at the Interface" J. Phys. Chem. Lett. 2 (2011) 3130.

${ }^{6}$ E.S. Ilton, P.S. Bagus, "XPS determination of uranium oxidation states" Surf. Interface Anal. 43 (2011) 1549.

${ }^{7}$ H. Idriss, "Surface reactions of uranium oxide powder, thin films and single crystals" Surf. Sci. Rep. 65 (2010) 67.

${ }^{8}$ M. Schindler, F.C. Hawthorne, M.S. Freund, P.C. Burns, "XPS spectra of uranyl minerals and synthetic uranyl compounds. II: The O 1s spectrum" Geochim. Cosmochim. Acta 73 (2009) 2488.

${ }^{9}$ S.D. Senanayake, G.I.N. Waterhouse, A.S.Y. Chan, T.E. Madey, D.R. Mullins, H. Idriss, "The reactions of water vapour on the surfaces of stoichiometric and reduced uranium dioxide: A high resolution XPS study" Catal. Today 120 (2007) 151.

${ }^{10}$ K. Grossmann, T. Arnold, R. Steudtner, S. Weiss, G. Bernhard, "Visualizing different uranium oxidation states during the surface alteration of uraninite and uranium tetrachloride" Naturwissenschaften 96 (2009) 963.

${ }^{11}$ G. Leinders, J. Pakarinen, R. Delville, T. Cardinaels, K. Binnemans, M. Verwerft, "LowTemperature Oxidation of Fine $\mathrm{UO}_{2}$ Powders: A Process of Nanosized Domain Development" Inorg. Chem. 55 (2016) 3915.

${ }^{12}$ T. Bo, J.H. Lan, Y.L. Zhao, Y.J. Zhang, C.H. He, Z.F. Chai, W.Q. Shi, "First-principles study of water adsorption and dissociation on the $\mathrm{UO}_{2}(111),(110)$ and (100) surfaces" J. Nucl. Mater. 454 (2014) 446.

${ }^{13}$ T. Bo, J.H. Lan, C.Z. Wang, Y.L. Zhao, C.H. He, Y.J. Zhang, Z.F. Chai, W.Q. Shi, "FirstPrinciples Study of Water Reaction and $\mathrm{H}_{2}$ Formation on $\mathrm{UO}_{2}$ (111) and (110) Single Crystal Surfaces" J. Phys. Chem. C 118 (2014) 21935.

${ }^{14}$ P.J. Hay, Theoretical studies of hydrogen and water adsorption on actinide oxide surfaces, Mater. Res. Soc. Symp. Proc. 893 (2006) 363.

${ }^{15}$ P. Maldonado, L.Z. Evins, P.M. Oppeneer, "Ab Initio Atomistic Thermodynamics of Water Reacting with Uranium Dioxide Surfaces" J. Phys. Chem. C 118 (2014) 8491.

${ }^{16}$ X. Tian, H. Wang, H. Xiao, T. Gao, "Adsorption of water on $\mathrm{UO}_{2}$ (111) surface: Density functional theory calculations" Comput. Mater. Sci. 91 (2014) 364.

${ }^{17}$ P.F. Weck, E. Kim, C.F. Jové-Colón, D.C. Sassani, "On the role of strong electron correlations in the surface properties and chemistry of uranium dioxide" Dalt. Trans. 42 (2013) 4570.

${ }^{18}$ J. Hubbard, "Electron correlations in narrow energy bands" Proc. R. Soc. London A 276 (1963) 238. 
${ }^{19}$ J. Stultz, M. T. Paffett, and S. A. Joyce, "Thermal Evolution of Hydrogen Following Water Adsorption on Defective $\mathrm{UO}_{2}(100)$ " J. Phys. Chem. B. 108 (2004) 2362

${ }^{20}$ S. Cohen, M.H. Mintz, S. Zalkind, A. Seibert, T. Gouder, N. Shamir, "Water chemisorption on a sputter deposited uranium dioxide film - Effect of defects" Solid State Ionics 263 (2014) 39.

${ }^{21}$ M.N. Hedhili, B.V. Yakshinskiy, T.E. Madey, "Interaction of water vapor with $\mathrm{UO}_{2}(001)$ " Surf. Sci. 445 (2000) 512.

${ }^{22}$ A.L. Tamasi, K.S. Boland, K. Czerwinski, J. K. Ellis, S. A. Kozimor, R. L. Martin, A. L. Pugmire, D. Reilly, B. L. Scott, A. D. Sutton, G. L. Wagner, J. R. Walensky, M. P. Wilkerson, "Oxidation and Hydration of $\mathrm{U}_{3} \mathrm{O}_{8}$ Materials Following Controlled Exposure to Temperature and Humidity" Anal. Chem. 87 (2015) 4210.

${ }^{23}$ A.J. Nelson, T.C. Meier, C.K. Saw, L.V. Griffith, "Surface and bulk chemistry of calcined $\mathrm{UO}_{2}$ powders" J. Vac. Sci. Technol. A. 21 (2003) 762.

${ }^{24}$ J.C. Riviere, Instumentation, in: D. Briggs and M.P. Seah (Eds.), Practical Surface Analysis by Auger and X-ray Photoelectron Spectrocopy, Wiley, Chichester, 1983, pp. 17-84.

${ }^{25}$ H. Estrade-Szwarckopf, "XPS photoemission in carbonaceous materials: A "defect" peak beside the graphitic asymmetric peak" Carbon 42 (2004) 1713.

${ }^{26}$ M. Schindler, F.C. Hawthorne, M.S. Freund, P.C. Burns, "XPS spectra of uranyl minerals and synthetic uranyl compounds. I: The U 4f spectrum" Geochim. Cosmochim. Acta 73 (2009) 2471. 